\title{
¿Por qué la arquitectura es música congelada? Schelling, Le Corbusier y Xenakis
}

Virginia López-Domínguez

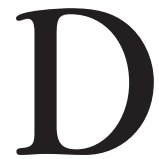
urante la travesía en barco que Le Corbusier hizo de vuelta a Europa, tras un exitoso viaje por Sudamérica, escribió sus impresiones acerca de las ciudades que había visitado, intentando reconstruir las conferencias dadas en Buenos Aires y modelando sus recuerdos a partir de las ideas expuestas durante su gira. El conjunto de aquellos escritos y dibujos, pletóricos de una sensibilidad que, sin escatimar el rigor conceptual, rayan a veces en la poesía, muestran a un hombre apasionado a la vez por la naturaleza y la arquitectura. Poco más tarde, en 1930, fueron publicados en París bajo el título de Precisions sur un état présent de l'architecture et de l'urbanisme. En el mismo prólogo, mientras el buque se adentraba en la mar y se silenciaban los ecos de la algarabía musical de Salvador de Bahía, Le Corbusier escribió un párrafo magistral:

Arquitectura y música son las manifestaciones de la dignidad humana. De ahí que el hombre afirma: "existo: soy un matemático, un geómetra, y soy religioso, es decir que creo en un ideal gigantesco que me domina y que podría alcanzar.

Arquitectura y música son unas hermanas muy íntimas: materia y espiritualidad, la arquitectura está en la música y la música está en la arquitectura. Y en ambas, un corazón que tiende a enaltecerse. ${ }^{1}$

Más de veinte años después, esa idea cristalizaba en su más alta expresión, gracias a la colaboración con Iannis Xenakis, en el diseño del Monasterio de Sainte Marie de La Tourette (1953) y del Pabellón Philips de la exposición de Bruselas de 1958.

${ }^{1}$ Le Corbusier, Precisiones. Respecto a un estado actual de la arquitectura y el urbanismo. Buenos Aires, Apóstrofe, s/a, pp. 27 y ss. 
No hay duda de que el interés actual que suscita la alianza entre la arquitectura y la música remite a los iniciadores del movimiento moderno, y es su impulso inspirador lo que ha convertido la frase: "la arquitectura es música congelada" casi en un lugar común, en un lema que permite fundar el derecho de la arquitectura a erigirse en una de las bellas artes, donde la utilidad pasa a un segundo plano frente a la búsqueda de la belleza. Sin embargo, la popularización del lema ha provocado una enorme injusticia con quien lo creó, porque hoy se atribuye la frase a diferentes autores: Goethe, Schopenhauer, Fr. Schlegel, Mme. de Stäel o Henry Crabb Robinson y, cuando por fin se acierta con el autor, se recalca su carácter intuitivo aislándola de su contexto, como si simplemente se tratara de una ocurrencia genial. ${ }^{2}$ El resultado es que así se destruyen las diferentes capas semánticas que convergen en la idea original, se la desconecta de una ontología estética y de toda una concepción del universo que podría servir para profundizar, por ejemplo, en el párrafo de Le Corbusier antes citado. En definitiva, se la condena a una superficialidad que oscurece su futura utilización y vuelve irrelevante la comparación debido al uso que de ella hizo la posteridad.

La frase surgió en lengua alemana: "Die Architektur ist die erstarrte Musik". El verbo erstarren se aplica a un flujo que se detiene y se estanca, a un fluido que se solidifica, a un movimiento que se paraliza o a una articulación que se anquilosa por falta de flexibilidad. Así pues, la expresión aparece con ciertas variaciones al ser traducida en español, por ejemplo, como música congelada, petrificada o fijada. Su primer registro se encuentra en la parte especial de lo que hoy conocemos como la Filosofía del arte de Schelling (sección IV), donde se construyen las formas particulares del arte a partir de la oposición de dos series, la real y la ideal, y, más concretamente, en los parágrafos dedicados a las artes figurativas. ${ }^{3}$ Esta obra, editada tras la muerte de Schelling por su hijo, recoge los manuscritos sobre los cuales el filósofo se apoyó para impartir lecciones en la Universidad de Jena en el semestre de invierno de 1802-1803, repetidas en Würzburg dos años más tarde.

La confusión en torno a la autoría de la frase se debe a su difusión con anterioridad a la publicación del libro. Por lo pronto, se sabe que Mme. de

2 Éste es el caso de Gastón Clerc González, La arquitectura es música congelada. Tesis. Madrid, Escuela Técnica Superior de Arquitectura, Departamento de Estética y Composición, 2002/2003, una tesis doctoral documentadísima, donde se acierta en la autoría original de la frase y se recogen con detalle los derroteros que sufrió la transmisión, pero se desconoce completamente el contexto filosófico en el que aparece.

${ }^{3}$ F. W. J. Schelling, Filosofía del arte. Estudio preliminar, trad. y notas de Virginia López-Domínguez. Madrid, Tecnos, 1999, p. 289. Asimismo, "la arquitectura abarca totalmente la música, de manera que un bello edificio de hecho no es otra cosa que música percibida con la vista, un concierto de armonías y combinaciones armónicas captado, no en la serie temporal, sino en la espacial (simultáneamente)" (ibid., p. 313). 
Stäel llegó a Weimar cuando las clases habían finalizado y, dado su interés por conocer el contenido de las mismas, solicitó la intervención del duque Carlos Augusto, quien la puso en contacto con un alumno inglés, Henry Crabb Robinson, quien había asistido al curso y, con el correr de los años, se convertiría en introductor del romanticismo en Gran Bretaña. De Stäel leyó sus apuntes y mantuvo con él varias entrevistas para debatir los temas tratados. Finalmente, embelesada por la potencia especulativa y el poder de sugerencia de las concepciones estéticas de Schelling, utilizó sus expresiones en algunas de sus obras posteriores, por ejemplo, en su novela Corinne (1807), al describir la catedral de San Pedro en Roma como una música continua y fija. ${ }^{4}$

Veinte años más tarde, Goethe creaba una variante de aquella definición y la consignaba en sus papeles. La arquitectura se presentaba ahora como música silenciada o muda (verstummter Tonkunst), ${ }^{5}$ recordando a Orfeo, quien construía casas con liras. Sin embargo, no era extraño que Goethe se atribuyese ideas de otros o, como en este caso, traspapelara notas tomadas ante un pensamiento inspirador sin indicar su procedencia. Así, en una conversación de 1829 con su secretario Eckermann, le contaba que había encontrado entre sus papeles una hoja en la que denominaba a la arquitectura "música congelada", confesándole que "realmente hay algo de esto, [porque] el estado de ánimo inducido por la arquitectura recuerda al suscitado por la música". ${ }^{6}$ Está claro que la metáfora literaria había producido un gran impacto en Goethe porque, en la segunda parte del Fausto, volvía a utilizarla, de la misma manera que lo había hecho Mme. de Stäel en Corinne, refiriéndola a la catedral de San Pedro. Y, para mayor coincidencia, la enmarcaba en el contexto de la arquitectura griega, con evidente alusión al estilo dórico, igual que como aparecía en la Filosofía del arte de Schelling: "Saludad ahora a una obra maestra del espíritu; pues he aquí que las nubes se disipan en música al marcharse. De los etéreos

${ }^{4}$ A.-L. G. Necker de Stäel, Corinne. París, Garnier Frères Libraires Éditeurs, 1807, libro IV, cap. 3. Sobre esta cuestión, véase la obra de J. Gibelin, L'esthétique de Schelling et l'Allemagne de Mme. de Stäel. París, Libraire Ancienne Honoré Champion, 1934, pp. XI-XIII.

${ }^{5} \mathrm{~J}$. W. Goethe, Goethes Gedanken über Musik. Eine Sammlung aus seinen Werken, Briefen, Gesprächen und Tagebüchern. Ed. de H. Walwei-Wiegelmann. Leipzig, Insel Verlag, 1985, p. 67, nota 10.

${ }^{6}$ En su libro Danubio (Barcelona, Anagrama, 6a. ed., 2003, cap. 3, pp. 126 y ss.), Claudio Magris refiere, al hablar de la ciudad de Linz, que allí vivió la "Suleika de Goethe", Marianne Jung, quien no sólo inspiró el personaje literario de El diván orientaloccidental, sino que escribió algunos de los más bellos poemas de la obra, que regaló al escritor alemán. Hasta después de la muerte de ella no se supo nada de esta incidencia. En cuanto a la atribución de la frase de Schelling a sí mismo, véase J. P. Eckermann, Gespräche mit Goethe in den letzten Jahren seines Leben. Leipzig, Brockhaus, 18361848 , t. I, 23 de marzo de 1829, p. 457. 
sonidos fluye una fuerza que nadie puede ver, pues, al moverse, todo es melodía; retumban los fustes y los triglifos, parece que cantase todo el templo". ${ }^{7}$

La metáfora musical de la basílica de San Pedro, basada en la conjunción de ideas pitagóricas sobre la concepción musical del cosmos con ideas masónicas sobre Dios como el gran arquitecto universal, se hizo recurrente y así, volvemos a encontrarla en las Memorias de un músico romántico como Berlioz: "Atraídos por la luz, mis ojos se alzaron hacia la gloriosa cúpula de Miguel Ángel y mis ideas experimentaron una abrupta transformación [...]: pasé, en un instante, a la Música de las Esferas, al coro de serafines, a la bondad y a la serenidad, y a la paz infinita de los cielos". 8

Más concretamente, la asociación entre el orden dórico y la música se convirtió en un tópico reincidente gracias a la difusión de dicha idea a través de Goethe. Por ejemplo, en un ensayo sobre la arquitectura estadounidense del famoso escultor Horatio Greenough se indicaba que el templo griego "pierde su armonía si en la ejecución se omite una nota". 9

Al margen de las ideas de Mme. de Stäel y de la impronta que tuvieron en la estética romántica, lo fascinante del tratamiento hecho por Schelling de las artes particulares y su interrelación, es que no se funda en conexiones empíricas ni azarosas sino que es el resultado de una construcción sistemática a priori, sin la cual el filósofo probablemente no hubiese llegado a asociar la música con la arquitectura ni a desarrollar semejante analogía con tanta profundidad.

Como corresponde a toda visión idealista, el punto de partida para establecer estas conexiones son procesos espirituales, más concretamente, procesos cognitivos o modos de representación. Se trata de los movimientos mediante los cuales la conciencia perfila activamente el mundo que la rodea, construyendo síntesis entre lo inteligible y lo sensible, siempre gracias a la facultad de la imaginación. Para Schelling, estos procedimientos son tres: el esquema, la alegoría y el símbolo. El esquema reúne lo general, lo uno, lo universal, lo eterno (esto es, el concepto) con lo particular, lo múltiple, lo individual y temporal (esto es la sensación) a través de una subsunción de la última al primero. Lo intuido sensiblemente se subordina al concepto y gracias a ello sale de la esfera de lo exclusivamente subjetivo para alcanzar una cierta objetividad. Lo

${ }^{7}$ J. W. Goethe, Fausto. Ed. bilingüe de Helena Cortés. Madrid, Abada, 2010, II, NI, p. 660.

${ }^{8}$ Las ideas masónicas en Alemania se difundieron sobre todo a partir de la publicación de Diálogos para masones (1776) de G. E. Lessing. Muchos de los intelectuales de la época, por ejemplo, Lessing o Fichte, pertenecieron a este grupo. Véase H. Berlioz, Memorias. Madrid, Akal, 2017. Texto citado por G. Clerc González, op. cit., p. 493.

${ }^{9} \mathrm{H}$. Greenough, Form and function. Remarks on Art, Design and Architecture. Berkeley, Universidad de California, 1966, p. 56. Esta obra es una selección de escritos de Greenough, que intentó compilar en 1852 con el título de The Travels. Observations and Experiences of a Yankee Stonecutter. 
ideal se vuelve entonces real. Este último lo acoge dentro de sí de una manera directa, convirtiéndose en un caso particular de aquél. De este modo -digámoslo con las palabras de Schelling- el esquema significa lo particular, pero no lo es. Así ocurre en todas las lenguas, ya que, aunque nos refiramos a las cosas particulares, lo hacemos siempre a través de términos generales. ${ }^{10}$ Lo mismo sucede en la aritmética y la geometría. Y esto es así porque el esquema construye el saber en general. Por supuesto, también acontece en las dos artes vinculadas primariamente a dichas ciencias: la música y la arquitectura, que, evidentemente, proceden de una manera esquemática. La alegoría, en cambio, realiza el movimiento contrario: va de lo particular a lo general. Desde lo real apunta a lo ideal, pero no lo es, nunca llega a identificarse completamente con él. Por eso, en las artes alegóricas, como la pintura o el bajorrelieve, predomina lo finito en el objeto artístico. Lo particular se revela en toda su caducidad contrastando con lo infinito hacia el que tiende, de un modo parecido a como ocurre en la acción, al concretarse en actos que aspiran a un proyecto ideal, pero sólo lo realizan en parte, esto es, con limitaciones propias de la concreción. ${ }^{11}$ Finalmente, en el símbolo se reúnen los dos movimientos, el que va de lo ideal a lo real y viceversa. Se opera entonces la síntesis del esquema con la alegoría, de tal manera que la imagen y su referente convergen produciéndose el máximo punto de unión entre logos y ser. De ahí que el símbolo sea y, al mismo tiempo, signifique, y que Schelling eluda la palabra Symbol para referirse a él y, en cambio, utilice el término Sinnbild, como lo que reúne la imagen con el sentido. ${ }^{12}$

En el mundo natural, el símbolo por excelencia es el organismo, porque refleja perfectamente la razón, como ya habían visto Kant y Fichte. ${ }^{13}$ En el ámbito de las bellas artes, la plástica posee un carácter simbólico y, puesto que se compone de otras tres artes: la arquitectura, el bajorrelieve y la escultura, esta última es la que consigue llevarlo a su máximo esplendor. A su vez, entre las actividades humanas, entre las potencias espirituales, está

${ }^{10}$ F. W. J. Schelling, op. cit., pp. 70 y ss.

${ }^{11}$ Ibid., pp. 72 y ss.

${ }^{12}$ Idem. Probablemente, Schelling desecha la palabra Symbol porque en la Alemania de su época este término se vincula al símbolo religioso, por lo que su utilización en filosofía sería cuestionable y sospechosa. Pero, sobre todo, la palabra de origen germano Sinnbild recoge mejor lo que Schelling quiere expresar. Obsérvese que para él el arte es reflejo de la naturaleza y ésta, una irradiación del mundo eidético, es decir, que todo es imagen (Bild) de lo absoluto, que se concentra.

${ }^{13}$ I. Kant, $K r V$, BXXIII; BXXXVII y ss.; $₫ 27$, B 166-168; B 860 y ss.; A 832 y ss. En cuanto a Fichte, el cuerpo humano es el símbolo de la razón, véase, por ejemplo, mi artículo "La imaginación en la Wissenschaftslehre nova methodo", en Fichte: Crença, imaginaçao e temporalidade. Ed. de Gil López-Domínguez y Couto Soares. Porto, Campo das Letras Editores, 2002, pp. 11-22. 
claro que la creación estética es, frente al saber y a la acción, la propiamente simbólica, porque genera un objeto que tiene una entidad, un perfil por sí mismo, pero lo trasciende al expresar una idea, es decir, que además de ser algo, lo significa. ${ }^{14}$

Como corresponde a una visión realista, surgida de la filosofía de la naturaleza, estos procesos subjetivos que acabamos de presentar también son reflejo de las fuerzas naturales y de su organización en tres potencias y en tres reinos, es decir, que las distintas artes reproducen en el nivel del espíritu los estratos naturales y su interrelación. Incluso cada una se mueve en una dimensión espacial específica que la define: la música en la línea, donde se configura la sucesión, la pintura en el plano y la plástica en la profundidad.

La música, que, por primera vez con Schelling, aparece en la clasificación de las bellas artes bajo el rubro de figurativa, tiene un vínculo muy profundo con la naturaleza porque en ella todo tiene un ritmo, un ciclo de vida o de movimiento, incluidos los cuerpos astronómicos. De hecho, los pitagóricos decían no sólo que todo es número, sino que todo tiene una correspondencia musical, de tal manera que hasta el movimiento planetario produce un sonido, sólo que ningún oído humano es capaz de oírlo. ${ }^{15}$

La música es la primera de las artes figurativas, de ahí que represente el movimiento como tal, depurado de los objetos. El ritmo, en cuanto que es su esencia, está necesariamente ligado a las formas naturales primigenias, en particular, a los cuerpos inorgánicos, como los metales, cuya sonoridad depende de su cohesión y, por tanto, de la gravedad primordial del universo físico, justamente de la característica general de la materia, según Schelling. El órgano del cuerpo que permite la captación del sonido, el oído, reproduce la asociación con el magnetismo en un nivel de mayor perfección, y está constituido en su exterior analógicamente, por cuerpos rígidos y sonoros. ${ }^{16}$ De este modo, la música humana aparece como reflejo de la armonía de la naturaleza visible, como transcripción del movimiento de los cuerpos celestes, donde las figuras se muestran surgiendo del caos mismo, presentadas en la pura forma del movimiento, abstraídas de lo corpóreo. Es por eso que siendo éste el arte más primitivo, sin embargo, se le atribuye una espiritualidad y una inmaterialidad cercana a la del lenguaje. ${ }^{17}$ De algún modo, las artes discursivas son una potenciación de las figurativas en el plano del espíritu, de modo que la poesía no es más que música, ritmo convertido en lenguaje,

${ }^{14}$ F. W. J. Schelling, op. cit., pp. 73 y ss.

15 Ibid., pp. 196-197. Además, se atribuye a Pitágoras el descubrimiento de la relación entre el aspecto cualitativo del sonido (las notas de la escala) y su determinación cuantitativa en la longitud de cuerda de la lira.

${ }^{16}$ Ibid., pp. 181 y ss.

${ }^{17}$ Ibid., pp. 195 y ss. 
expresado de forma claramente racional, y no emotiva, como sí ocurre en esta última. ${ }^{18}$

En segundo lugar, dentro de las artes figurativas, la pintura corresponde a la luz, que es la siguiente de las potencias de la naturaleza. Ella es capaz de subordinar lo particular a lo universal sin suprimir la diferencia, haciendo simultáneo en el espacio lo que antes se mostraba como sucesión e impregnando con la idea las dos dimensiones de la materia. Finalmente, las artes plásticas representan la tercera potencia: la del organismo.

Como primer nivel de las artes plásticas, la arquitectura ocupa en este ámbito un lugar similar al que la música ocupa en relación a la esfera inorgánica. Tiene que ver con el reino vegetal, el más sencillo y primario de los tres, mientras que el bajorrelieve plasma mejor el medio animal, y la escultura, el mundo humano. Con esta última, las artes figurativas alcanzan su culminación para dar paso a las artes discursivas, que se desarrollan en el terreno del lenguaje, de ese fenómeno que constituye, precisamente, el patrimonio exclusivo de la humanidad. ${ }^{19}$

Además, esta concepción orgánica de sistema implica que en cada parte está presente la totalidad, por tanto, cada una de las artes reaparece en algún aspecto de las otras y refleja a todas las demás. Así, por ejemplo, el dibujo es el lado musical o rítmico de la pintura, el claroscuro es la pintura en la pintura y el colorido, en la medida en que consigue mostrar la perspectiva, es la plástica en la pintura. Pero también se trata de un sistema genético, donde cada una, como si fuera un embrión, da lugar a la siguiente, formando un movimiento continuo cuyo fin es desplegar de forma paulatina la espiritualidad. Primero, a través de las artes figurativas, que, todavía apegadas a la materia, recorren los distintos reinos de la naturaleza; para finalmente ascender a través del mundo humano, de la esfera del logos, del lenguaje, gracias a las artes discursivas; y de este modo llegar al grado máximo, esto es, a la libertad más plena, expresada en la tragedia. Es como si se desenvolvieran en un movimiento en espiral, algo así como un remolino nacido desde la tierra, en cuyo ascenso pasa una y otra vez por el mismo lugar, pero estableciendo en cada caso un punto de mira más abarcador y elevado; un flujo de energía que se plasma en toda cla-

${ }^{18}$ En sus conversaciones con Eckermann, Goethe afirma que "de la música emana una fuerza que nadie acierta a explicar", porque ella "es el lenguaje del corazón" (J. W. Goethe, op. cit., pp. 457 y ss.) Una idea semejante aparece también en Schopenhauer cuando sostiene que la música revela la voluntad en su lucha universal por afirmarse a sí misma, es decir, que se trata de un arte dirigido al sentimiento, a lo irracional, y precisamente por eso puede ser compartido por individuos que hablen lenguas distintas o posean niveles culturales diferentes. Al respecto, véase C. J. González Serrano, Arte y música en Schopenhauer. El camino hacia la experiencia estética. Madrid, Locus Solus, 2016.

${ }^{19}$ F. W. J. Schelling, op. cit., pp. 162 y ss. 
se de imágenes y sintetiza en cada producto la razón con el sentimiento y la sensibilidad, lo consciente con lo inconsciente; una fluencia, que ni siquiera se detiene cuando llega a la tragedia, sino que desciende nuevamente en su opuesto, la comedia, para regresar hacia la figuración, generando nuevas artes, algunas apenas esbozadas, como el canto o la danza, para volver a iniciar el recorrido. ${ }^{20}$

En definitiva, el arte constituye una totalidad de fuerzas o potencias, donde cada disciplina, cada obra, cada estilo, cada movimiento, cada artista, ocupa un lugar necesario, irrenunciable e intransferible, que cobra sentido con relación al conjunto. En su aparición histórica, los productos estéticos van construyendo un mundo, una grandiosa teofanía, que surge desde la dinámica divina de la imaginación actualizada en cada uno de los artistas. Ellos traen a la luz lo absoluto, en su plenitud, sí, pero contraído en ideas, porque un desvelamiento completo de la totalidad resquebrajaría cualquier visión. ${ }^{21}$ Estas ideas se encarnan en las diferentes producciones estéticas a través de la peculiaridad de los individuos, épocas y técnicas. Cada una a su manera plasma lo absoluto desde una cierta perspectiva y, en su conjunto, todas muestran el orbe ideal, el mundo de los dioses olímpicos. De ahí que para Schelling la mitología constituya la auténtica materia estética. ${ }^{22}$ En suma, el arte imita el poder absoluto de la creación universal, de la totalidad única y divina, pero, como no puede plasmarlo ni en toda su intensidad ni en su plena variedad, lo refleja sintetizándolo con lo finito, en una mezcla de panteísmo y politeísmo, que ha dado en llamarse "panenteísmo". ${ }^{23}$ De esta manera, el arte presenta lo absoluto en lo finito, desvelando la infinidad de sus matices, tanto de lo bueno como de lo malo, de lo bello y lo feo, de lo amoroso y lo terrible, de la felicidad y el dolor. Finalmente, la filosofía, al desarrollar esa cadena de actos en un proceso, que es la historia misma del arte, también consigue construir el universo entero, sólo que visto desde una perspectiva estética. ${ }^{24}$

20 "La poesía retorna a la música en el canto, a la pintura en el baile (en parte en la medida en que es ballet, en parte en cuanto es pantomima), a la verdadera plástica en el arte dramático, que es una plástica viviente" (ibid., p. 492).

${ }^{21}$ Ibid., $\$ \$ 25-27$, pp. $45-48$ y ss.

22 Ibid., \§ 28 y ss., pp. $48-55$ y ss.

${ }^{23}$ La expresión "panenteísmo" fue utilizada por primera vez por K. Ch. Krause para referirse a su propio sistema, donde presenta un absoluto inmanente a lo finito sin destruir la individualidad y libertad de este último. El término es también perfectamente aplicable a la filosofía que Schelling hace en esta época, en la que combina armoniosamente el panteísmo con el politeísmo, y así ha sido usado ya por Pareyson para calificar el sistema de la identidad. Cf. L. Pareyson, Schelling. Presentazione e antologia. Turín, Marietti, 1975, p. 47.

${ }^{24}$ F. W. J. Schelling, op. cit., pp. 16-22. 
Desde la óptica individual, esta visión sacraliza la tarea artística al interpretarla como un modo de restaurar la actividad divina de creación. Dice Schelling en su diálogo Bruno que tanto el filósofo como el artista realizan un culto o un servicio divino. El primero lo profesa de forma consciente en su interior, como conocimiento, mientras que el segundo lo hace exteriormente y sin saberlo, o sea, como revelación. De esta forma, la filosofía y la poesía cumplen en la cultura moderna igual misión que los misterios y la mitología en la Antigüedad, y reproducen su mutua relación: la filosofía construye un conocimiento esotérico y secreto que se objetiva, se hace accesible al gran público y se vuelve exotérico a través del arte. ${ }^{25}$ Esto es posible porque en su núcleo más íntimo, el arte reposa en una experiencia religiosa, extática, que trasciende los límites particulares de cada artista y termina por negar su Yo particular, anegado o entregado a la pura acción creadora y, por tanto, divina. Esto es lo que Schelling llama "intuición intelectual", ${ }^{26}$ es decir, el punto de partida de la filosofía, que se objetiva en la intuición estética, por lo cual ésta representa la prueba y el documento de la otra, que es puramente subjetiva. ${ }^{27}$ Aquí se encontraría la base de la empatía, que permite asumir posiciones distintas a la propia para delinear, por ejemplo, los personajes de una novela o para diseñar un edificio atendiendo a sus habitantes o usuarios y, a la vez, enmarcándolo en la naturaleza o en la ciudad. Debido a esa flexibilidad, a esa capacidad para cambiar de uno a otro punto de vista, se forma una red de sentido, un ámbito en el que todo interpela a todo y donde es esencial mantener el respeto a lo otro (sean los demás, la naturaleza o lo absoluto). Según mi opinión, gracias a ello, el hombre descubre su lugar en el universo, esa identidad puntual y a la vez fluyente, que necesariamente remite a todos los demás seres y, en última instancia, apunta a lo divino, conduciendo -como dice Xenakis- del arte a la religión. ${ }^{28}$ Se descubre así lo que Le Corbusier llamaba "dignidad" en

${ }^{25}$ F. W. J. Schelling, "Bruno", en F. W. J. Schelling, Sämmtliche Werke. Ed. de K. F. A. Schelling. Stuttgart/Augsburg, Cotta, 1856-1861, t. IV, pp. 231 y ss.

${ }^{26}$ F. W. J. Schelling, "Cartas filosóficas sobre dogmatismo y criticismo", en F. W. J. Schelling, Sämmtliche Werke, carta 8. Sobre este tema, pueden verse mis artículos: "Del Yo a la naturaleza por el camino del arte", en El inicio del idealismo alemán. Madrid, Servicio de Publicaciones UCM/UnED, 1996, pp. 281-289; "Die Entwicklung der intellektuellen Anschauung bis zur Darstellung der Wissenschaftslehre (1801-1802)", en Fichte-Studien 20, 2003, pp. 103-115 y "Sujeto y modernidad en la filosofía del arte de Schelling", en Ideas. Revista de Filosofía Moderna y Contemporánea, núm. 1, julio de 2015, pp. 80-108. [www.revistaideas.com.ar.]

${ }^{27}$ F. W. J. Schelling, "Introducción, cap. 6 y Nota general a todo el sistema", en Sistema del idealismo trascendental. Introd., trad. y notas de Virginia López-Domínguez y Jacinto Rivera de Rosales. Madrid, Ánthropos, 1988.

${ }^{28}$ Iannis Xenakis, Musiques formelles. Ed. de Richard-Masse. París, La Revue Musicale, núms. 253-254, 1963, p. 15. 
el texto anterior, utilizando la expresión casi en el mismo sentido que Pico della Mirandola. ${ }^{29}$

Por otra parte, desde el punto de vista de la obra y ya no desde el del sujeto, la flexibilidad del movimiento creador, que fluye de manera ininterrumpida y apunta de una arte hacia otra inscribiendo sugerencias y haciendo resonar ecos entre ellas, pone en evidencia que la actividad estética tiene una completa unidad, aunque se explaye en matices, modulaciones y diferentes técnicas. En los artistas, esta unidad, esta integración de las distintas artes, se concreta en el gusto por la sinestesia o en la búsqueda de la obra total, de lo que Wagner llamó Gesamtkunstwerk y trató de llevar a la práctica a través de la ópera. También Schelling ve en la ópera esta posibilidad de globalización, ya que reúne diversas ocupaciones estéticas (como la música, el canto, el baile, la creación literaria, la pintura y la arquitectura de los decorados, la sastrería, etcétera). Por eso la sitúa al final del sistema después de su culminación en la tragedia, a pesar de reconocer que el arte operístico de su época no está todavía a la altura de semejantes exigencias y que sólo ha logrado plasmar una caricatura de la obra universal. ${ }^{30}$ A su vez, el deseo de trascender los límites de la arquitectura hacia otras artes aparece también en Le Corbusier y Xenakis. Un ejemplo se encontraría en el Pabellón Philips, ${ }^{31}$ construido para la Exposición Mundial de 1958 en Bruselas. Se trata de una obra compuesta de delgadas placas de hormigón, velas paraboloides e hiperbólicas sujetas por mástiles como

${ }^{29}$ En El discurso sobre la dignidad del hombre, Pico della Mirandola presenta al ser humano de una manera muy parecida a como lo hacen Schelling y los primeros románticos alemanes. El hombre es, como rezan los textos bíblicos imagen de Dios (imago dei) y, en su caso, esto significa que el Creador no le dio una configuración determinada, sino que lo dejó libre para que se haga a sí mismo, por lo que posee un poder de autocreación, una capacidad de autotransformación, infinitos.

${ }^{30}$ Richard Wagner, La obra de arte del futuro. 2a. ed. Trad. de Joan B. Llinares y Francisco López Martín. Valencia, Universidad de Valencia, [1840] 2007. Cf. F. W. J. Schelling, Filosofía del arte, pp. 492-493.

${ }^{31}$ La atribución del Pabellón Philips (Bélgica, 1958) a Le Corbusier ha sido puesta en duda. A pesar de que Xenakis no era arquitecto sino ingeniero y, sobre todo, músico y matemático, son numerosos los testimonios que dan cuenta de que el genial "ayudante" se hizo cargo completamente del proyecto arquitectónico, entre ellos, la entrevista de Bruno Serrou, colaborador de la revista de música Scherzo. Esta entrevista, una de las últimas que Xenakis concedió a la prensa, tuvo lugar los días 3 y 11 de diciembre de 1997 en París, en el marco del Festival "Presencias", patrocinado por Radio Francia, que le homenajeaba por su labor y larga trayectoria como músico. El Pabellón Phillips parece corresponderse más con las ideas rupturistas de Xenakis sobre la arquitectura que con el clasicismo formal de Le Corbusier. Además, Xenakis tenía un compromiso personal con la "música arquitectónica" de Varèse, ya que sus propias composiciones iban en la misma línea. Se trataba de una música basada en la "oposición de planos y volúmenes, como las obras del movimiento moderno" (cf. G. Clerc González, op. cit., p. 624). 
los de las tiendas bereberes, plásticos, tubos de acero y cables tensados; cuyo objetivo era crear un espacio envolvente, pero casi etéreo, para albergar uno de los primeros espectáculos audiovisuales que han existido en conjunción con la arquitectura, consistente en una sinestesia de luz, sonido y espacio (de acuerdo con los principios de la geometría matemática), a través de una experiencia multisensorial que reunía color, imagen, música, palabra y ritmo en el "Poema electrónico" de Edgard Varèse. De acuerdo con una entrevista que Xenakis concedió a la revista $E l$ Correo de la Unesco, la inspiración para el diseño surgió de sus experiencias en la composición musical:

Lo concebí - dijo entonces- basándome en ideas provenientes de la música para orquesta que yo componía en esa época. Quería crear espacios que se modificaran y transformaran continuamente a partir del desplazamiento de una recta, con lo cual se obtienen paraboloides hiperbólicos en el caso de la arquitectura y verdaderas masas de glissandi en música. ${ }^{32}$

Otro ejemplo de creación que persigue una interacción sinestésica se da en la composición electrónica de Xenakis titulada Noomena (1974), ideada en función de una arquitectura determinada para "ser difundida en el espacio arquitectónico de un gran cascarón de plástico". ${ }^{33}$ En estos dos casos, se concreta la teoría de Xenakis de que crear un espacio sonoro, es decir, un espacio musical, supone generar un universo completo cuya lógica o forma matemática es el álgebra, un ámbito donde se manifiesta un estímulo estético determinado para cada uno de los sentidos, de modo que la música ha de ser interpretada como expresión de toda una cosmovisión. ${ }^{34}$

Una vez establecida de un modo general la función de las artes y su interrelación, de inmediato asalta una pregunta, la de si la arquitectura puede entrar legítimamente en semejante sistema, o dicho de otra manera, si reúne las condiciones necesarias para considerarse una de las bellas artes. Esta preocupación se encuentra a la base del movimiento moderno, que la distinguió con claridad de la construcción, ligada a objetivos meramente utilitarios, como pueden ser la protección frente a las inclemencias del tiempo o la defensa ante enemigos, sean animales o humanos. Es indudable que la casa debe cumplir

${ }^{32}$ Entrevista a Iannis Xenakis: "Dimensión matemática de la música", en El Correo, Unesco, abril de 1986, pp. 4-8.

${ }^{33}$ Esta composición se dio a conocer en Madrid como base sonora del espectáculo que cerró el Festival de Otoño de 1985 en la Plaza de Toros de Las Ventas, acompañada por fuegos artificiales diseñados para la ocasión por Pierre-Alain Hubert. G. Clerc González, op. cit., pp. 608 y ss.

${ }^{34}$ I. Xenakis, Musiques formelles, cap. v. Cf. G. Clerc González, op. cit., p. 612. 
la función de refugio, ya que en ella se desarrollan los aspectos íntimos de nuestra existencia, pero si quiere ser -como dijo Le Corbusier- "el estuche de la vida, la máquina de la felicidad" ha de abrirse a otros horizontes. En este punto, Schelling es contundente. Para él, la arquitectura existe como arte cuando transciende la salvaguardia de los instintos, como la reproducción de la especie y la conservación de sus individuos. Mientras eso no se produzca, nos mantenemos dentro del dominio natural, donde imperan la repetición y la imitación. El impulso de formación (Bildundgstrieb), que guía la construcción de nidos, madrigueras o panales, no alcanza suficiente libertad como para transformarse en intuición estética. ${ }^{35}$ Sólo lo consigue cuando lo edificado deja de subordinarse de modo prioritario a la utilidad, en busca de un fin autónomo puramente expresivo. ${ }^{36}$

Pero, dado que esta independencia de lo necesario resulta muy limitada en la arquitectura, al final ella logra hacerse bella sólo cuando "se convierte en la potencia y la libre imitación de sí misma". ${ }^{37}$ Semejante autorreferencialidad, característica también de la razón y de la filosofía, produce la identidad objetiva de la cosa con el concepto, al desgajar la forma de la función, la apariencia de la necesidad, y al restablecer su unión armoniosa de manera espontánea, sin forzarla ni buscarla deliberadamente. ${ }^{38}$ Para probar tales afirmaciones, Schelling recurre al Tratado de arquitectura de Vitruvio, ${ }^{39}$ haciendo notar que el arte griego de la construcción, que alcanzó figuras tan bellas e incluso sirvió de modelo para otros pueblos, surgió de la mera imitación de las viviendas primitivas. Por ejemplo, las columnas reproducían los troncos que sostenían el techo y los triglifos del orden dórico escamoteaban, tras la bella apariencia, lo que en origen fueron cabezas salientes de los travesaños. ${ }^{40}$ Los edificios pudieron superar la carencia que venían a resolver y volverse símbolos que representan ideas, cuando la columna adoptó una base y se separó del suelo, del mismo lugar donde se entierra la planta y al que se liga el animal a través

${ }^{35}$ F. W. J. Schelling, Filosofía del arte, pp. 285-287.

36 Ibid., pp. 288-293.

${ }^{37}$ Ibid., p. 293.

${ }^{38}$ Un ejemplo muy interesante de la aplicación de la idea de autorreferencialidad que funda la arquitectura y de la búsqueda de la apariencia por la apariencia misma, se encuentra en algunas obras de Friedensreich Hundertwasser, por ejemplo, en la Hundertwasserhaus de Viena, donde la disposición de las ventanas y el colorido de la pintura hace que la casa "imite" en su fachada un conjunto de casas, más bien propias de otras latitudes.

${ }^{39} \mathrm{El}$ manual de Vitruvio es la única fuente que Schelling usa para elaborar esta parte de la Filosofía del arte, por eso, se concentra sobre todo en la arquitectura clásica griega. Ya en el primer libro de esta obra, Vitruvio señala que el conocimiento de la música es requisito imprescindible para el buen arquitecto.

${ }^{40}$ F. W. J. Schelling, Filosofía del arte, pp. 293-294 y 308 y ss. 
de sus patas y por la posición de su hocico, sobre todo, el cuadrúpedo. Así, al elevarse las columnas, como si se tratara de un atlante que se pone en pie sosteniendo el techo, la construcción presagió formas superiores de organización, apuntando ya a la figura humana. Representó la cabeza en los capiteles y la frente en los frontispicios de los templos, donde se inscribieron pensamientos e imágenes bajo la forma de frases y bajorrelieves, para finalmente rematar el proceso con la cúpula, a través de la cual se plasmó la bóveda celeste, el cosmos superior de las ideas. Entonces los edificios pasaron a formar parte del universo estético. ${ }^{41}$

De este modo, en la evolución desde el arte mecánico de la construcción, que imita las formas orgánicas, a la arquitectura, que está liberada de toda mímesis porque su fin consiste en imitarse a sí misma, se produce un círculo, un retorno a lo inorgánico desde los niveles más elevados - que ya señalamos como característica del sistema schellingiano de las bellas artes. En ese proceso, la arquitectura parte de lo inorgánico como material (de la piedra, del cemento, o incluso de la madera), pero, dado que lo que no está vivo nunca puede tener un significado simbólico sino únicamente una relación inmediata, esquemática, con la imaginación que lo plasma, la arquitectura se eleva por encima de la utilidad y de las técnicas mecánicas de construcción, para transformarse en arte convirtiendo el fin objetivo en subjetivo. Entonces, se limita a sugerir lo orgánico a través de lo inorgánico, sin poder alcanzarlo nunca porque, si lo hiciera, desvirtuaría su esencia. Así, al apuntar a lo orgánico, lo transforma en alegoría y, desde esta separación, de lo real y lo ideal, puede intentar la unión de ambos en lo simbólico, representando el organismo en lo inorgánico o las formas orgánicas preformadas en lo inorgánico: ${ }^{42}$

Está claro que la música y la arquitectura son ambos artes que no necesitan imitar cosas - dice Xenakis-; son los artes en los cuales la materia y la forma tienen que relacionarse más íntimamente que en cualquier otro lugar. Ambos admiten la repetición, una herramienta omnipotente; ambos se aplican a los efectos físicos del tamaño y de la intensidad, por medio de los cuales pueden asombrar los sentidos y la mente, uniformes a la aniquilación. Finalmente, su naturaleza

${ }^{41}$ Ibid., pp. 306 y ss. La explicación antropomórfica del templo como un ser que se levanta sobre la tierra, sin duda, está inspirada en el mito del anthropos, que se convierte en un ser bípedo y racional al elevarse desde su posición animal. Semejante analogía aparece tanto en las Metamorfosis de Ovidio (I, $85 \mathrm{~s}$.) como en las Ideas para la filosofía de la humanidad de Herder (I, 3, 6). Schelling conocía perfectamente ambas referencias. $C f$. "Significado simbólico de la figura humana", en F. W. J. Schelling, Filosofía del arte, p. 325.

${ }^{42}$ F. W. J. Schelling, Filosofía del arte, pp. 294 y ss. 
respectiva permite una abundancia de las combinaciones y de los progresos regulares que los conectan o comparan con la geometría y el análisis. ${ }^{43}$

A diferencia de la pintura o la escultura, la música es puramente expresiva y -como reconoce Schelling- resulta grotesca cuando recurre a la mímesis y se vuelve descriptiva. ${ }^{44}$ Lo mismo ocurre con la arquitectura, que constituye su correlato en las artes plásticas. En ambos casos, el resultado es que, al no buscarse una correspondencia con el mundo exterior, el artista se concentra en la interioridad del proceso creativo, y por eso en ambas artes se da el más íntimo engarce de la materia con la forma, como si la segunda surgiera de la primera. ${ }^{45} \mathrm{Y}$ esta unión tiene una estructura matemática, como pensaban los pitagóricos y Platón. Por estar vinculada a lo más primario, lo más ensimismado de la naturaleza (o sea, lo inorgánico y lo emocional), la música es un arte del tiempo y, en consecuencia, se relaciona con la aritmética. Ello se debe a que la música refleja lo interior y plasma el fluir mismo de la conciencia, que va de emoción en emoción, o de idea en idea (diánoia). En cambio, en la razón (nóesis) todo es sincrónico. La conciencia, que separa sujeto y objeto, no puede simultanear la totalidad racional ni la amplia gama de emociones sobre la que se asienta. Por eso, la distiende en un discurrir, desplegándose en una sucesión numérica o temporal. De ahí -según Schelling- la famosa frase de Leibniz: "la música es el arrebato del alma que no sabe que se numera a sí misma" ${ }^{46}$ Sin embargo, el filósofo no retoma esta asociación tanto de la

${ }^{43}$ Citado por N. González, en "Iannis Xenakis. Arquitecto de la música", en www. calgran.net/upf.

44 También Schelling critica el intento de imitar sonidos naturales en la música, por ejemplo, en La creación de Haydn, si bien es demasiado duro con él (Cf. F. W. J. Schelling, La filosofía del arte, pp. 189-190). Hace, además, una fuerte repulsa de la arquitectura gótica por imitar formas vegetales en las columnas y en los techos catedralicios, y desplaza su origen del arte godo al musulmán, que llegó a Europa desde España y se relaciona -siempre según Schelling- con la arquitectura hindú (ibid., pp. 299-301). Por otra parte, hay que reconocer que, en la pintura y en la escultura, sólo el estilo contemporáneo pudo hacer semejante trabajo de síntesis de la materia con la forma. Ello sucedió precisamente cuando se volvió abstracto.

${ }^{45}$ Se ha dicho, por ejemplo, que en Metástasis (1954), la composición musical que Xenakis realizó durante el diseño del convento de La Tourette, "la forma y la materia surgen de los procesos sonoros" (D. Desange: "Iannis Xenakis: Une approche philosophique", en Le philosophoire, num. 7, 1999/1, pp. 200-240).

${ }^{46}$ F. W. J. Schelling, Filosofía del arte, pp. 182-184. G. Leibniz, "Música es la actividad aritmética oculta del alma, que no es consciente de que está contando", de una carta de 27 de abril de 1712 a Christian Godbach; "musica est exercitium arithmeticae occultum nescientis se numerare animi”, Véase G. E. Guhrauer, Nachträge zu der Biographie Gottfried Wilhelm Freiherr von Leibnitz, 1846, p. 66. 
sugerencia leibniziana como de la "Estética trascendental" de Kant, donde las dos intuiciones puras de la sensibilidad, el tiempo y el espacio, fundan respectivamente la aritmética y la geometría. Dado que la arquitectura es un arte del espacio y, por tanto, se vale de la geometría, se puede afirmar que la fluencia interior se congela o se detiene al exteriorizarla. Así, el espacio podría definirse como alienación, cosificación o exteriorización del tiempo y, a la inversa, éste sería su interiorización. En consecuencia, la arquitectura es la música petrificada.

Desde la perspectiva de Schelling, también sería posible trastocar los términos y entonces decir que la música es la arquitectura hecha movimiento, fluyendo, haciéndose líquida, derritiéndose y escurriéndose por entre los pliegues del tiempo. Precisamente, esto es lo que quiso hacer Xenakis en sus composiciones: una musicalización de la arquitectura,${ }^{47}$ jugando con el hecho de que en ambas artes se manejan los mismos recursos mentales y que éstos reposan en una base común más profunda que los matemáticos denominan "estructura de orden". A la pregunta de si consideraba fundamental la correspondencia entre música y arquitectura, Xenakis respondió:

Goethe ha dicho que la arquitectura es música petrificada. Si se trata de ahondar esta fórmula, puramente literaria, para intentar una comprobación más objetiva, se llega enseguida a las estructuras mentales que pertenecen al tipo de los conjuntos. La rotación del rectángulo o las melodías son grupos de transformaciones. Y la teoría de los conjuntos trata precisamente de las simetrías hasta lo infinitamente pequeño de las partículas, que es la única manera de identificarlas. Hay pues diversos niveles de correspondencia. El más vago es el literario, como el de Goethe; yo he señalado otro, más objetivo, con el ejemplo de los conjuntos y otros más, de tipo diferente, como aquel de crear espacios sea sonoros, sea arquitectónicos, utilizando la línea recta acústica como los glissandi o la recta real.

Pero hay también otras maneras de ver. Por ejemplo, el ritmo. ¿En qué consiste? Se trata de escoger puntos en una recta del tiempo. El músico cuenta el tiempo de la misma manera que al marchar se cuentan los hitos kilométricos. Igual sucede en arquitectura, tratándose de una fachada, por ejemplo. Y las teclas del piano son también arquitectura: están dispuestas de manera constante. En un caso se trata del tiempo, en el otro del espacio. Hay pues una correspondencia entre los dos. Y

${ }^{47}$ En este sentido, resulta muy revelador el título de los escritos de Xenakis reunidos en Sharon Kanach, Música de la arquitectura. Madrid, Akal, 2009. 
ello es posible debido a que hay una estructura mental más profunda, aquello que los matemáticos llaman una estructura de orden. ${ }^{48}$

Así, definir el ritmo en la música significa encontrar ciertos puntos en la línea del tiempo, mientras que en la arquitectura se marcan puntos en el plano a lo largo de las rectas. La afinidad se revela incluso en los instrumentos musicales, por ejemplo, en las teclas del piano. Dispuestas mediante una distribución constante, configuran un espacio sonoro que repite doce notas elevándolas una octava de izquierda a derecha. La reiteración de lo homogéneo, es decir, el ritmo de la aparición de las teclas, da sentido a la sucesión mediante un orden que convierte el caos de lo múltiple en un espacio habitable, en un teclado musical que sirve como herramienta para la creación estética. En el caso de Xenakis, la justificación teórica de semejante correspondencia se encuentra en la física relativista de Einstein: a velocidades próximas a la luz (en torno a $\operatorname{los} 300000 \mathrm{~km} / \mathrm{s}$ ), la masa aumenta y el tiempo disminuye, con lo cual se puede suponer que ha de haber un punto donde todo es materia extendida en el espacio, o sea arquitectura, pero donde no existe el tiempo, es decir, que tampoco la música. En ese estado físico donde la energía se transforma en materia, el sonido, que es pura energía vibrante, se solidifica. Lo que para Xenakis marca la diferencia entre ambas artes en ese proceso es que el espacio en arquitectura es reversible, pero el tiempo en la música, no. ${ }^{49}$

De acuerdo con lo dicho hasta aquí, la correspondencia especular de ambas artes se da porque las dos se generan a partir de los mismos elementos. Así, para Schelling, la música contiene tres unidades:

1. Ritmo: es la configuración de la unidad en la multiplicidad. Se basa en la regularidad y la repetición de lo homogéneo. Se trata de una unidad real y cuantitativa. Gracias a esta coordinación que posibilita la síntesis, la sucesión adquiere un sentido, se vuelve una serie significativa. Schelling lo define como la música en la música y -según dijimos- lo relaciona con el magnetismo y con la longitud. Puede ser esquematizado mediante una línea aunque sólo implica el espacio en su primera dimensión, por lo que más bien representa el decurso temporal. ${ }^{50}$

${ }^{48}$ Entrevista a Iannis Xenakis, "Dimensión matemática de la música", en op. cit.,p. 6.

${ }^{49}$ I. Xenakis, Arts/Sciences: Alloys. Trad. de Sharon Kanach. Nueva York, Hildsdale, 1985, pp. 74 y ss. [Arts/Sciences: Alliages, Tournai, Casterman, 1979.]

${ }^{50}$ F. W. J. Schelling, Filosofía del arte, pp. 184 y ss. El esquema del magnetismo también se representa con una línea, ya que tanto la actividad centrífuga, que se expande desde el imán, como la centrípeta, que atrae a otro cuerpo metálico, surgen del mismo punto. Por su simplicidad, el magnetismo es la primera categoría de la física inorgánica. Véase F. W. J. Schelling, Sistema del idealismo trascendental, en Sämmtliche Werke, t. III, pp. 445 y ss. 
2. Modulación: es el arte de mantener el tono en la diferencia cualitativa. Constituye el principio ideal, representa la pluralidad, la individualidad y la disparidad. Remite a la segunda dimensión de la materia inorgánica: la electricidad y, por supuesto, se relaciona con la segunda potencia de la naturaleza, la luz. Digamos que la modulación se asemeja al color y, por eso, Schelling la considera como la pintura en la música. Desde el punto de vista geométrico, se asocia a la anchura o al plano. ${ }^{51}$

3. La síntesis de ritmo y modulación supone la aparición de la tercera dimensión del espacio: la profundidad, y la tercera de la materia: el proceso químico. En ella se da el paso de lo inorgánico a lo orgánico, por lo que Schelling la considera como la plástica en la música. La unión de ritmo y modulación puede efectuarse de dos maneras: cuando los elementos anteriores se subordinan al ritmo, a la sucesión, se tiene la melodía, por lo que se pone de relieve la unidad en la multiplicidad; cuando dependen de la modulación, de la coexistencia, surge la armonía, donde la multiplicidad se destaca por encima de la unidad. Estas dos síntesis servirán a Schelling para hacer una tipología musical correspondiente a las distintas etapas de la música. La música antigua es melódica y en ella se da una subordinación al ritmo, a lo real, como ocurre con el canto gregoriano. La música moderna, en cambio, es armónica, apunta a lo ideal, crea dispersión, por ejemplo, en la polifonía y, por eso, ella termina por unirse al discurso, a partir de la invención del contrapunto, que es un descubrimiento del periodo gótico. Planteada de esta manera, la evolución de la música va desde lo real, esencial y necesario, a lo ideal, accidental y contingente. ${ }^{52}$ La misma clasificación se utiliza para referirse al movimiento universal: en los planetas predomina el ritmo, por tanto, la melodía, y en los cometas, la armonía, es decir, la individualidad y la originalidad, que convierte su aparición en una fiesta esperada, sí, porque también es resultado de una reiteración que, sin embargo, se produce con escasa frecuencia. ${ }^{53}$ Las unidades que estructuran la música reaparecen en la arquitectura. El ritmo, que expresa la distribución periódica de lo homogéneo, se muestra en el tiempo a través de intervalos, y en el espacio, mediante distancias. ${ }^{54}$ Siguiendo siempre a Vitruvio, Schelling interpreta la utilización de las columnas en los templos como una ordenación rítmica, en la cual lo bello, lo agradable, está estrechamente relacionado con la necesaria seguridad y firmeza del edificio. A esta última ley responde también el hecho de que las columnas griegas sean más anchas en su base que en su cúspide. ${ }^{55}$

${ }^{51}$ F. W. J. Schelling, Filosofía del arte, pp. 186 y ss.

52 Ibid., pp 187-196.

53 Ibid., pp. 197 y ss.

${ }^{54}$ Ibid., pp. 307-308.

${ }^{55}$ Ibid., pp. 293-294 y 307 y ss. 
En el caso del monasterio de Sainte Marie de La Tourette, el ritmo se consigue en el diseño de la fachada a través de dos composiciones:

En la parte superior, se logra gracias al efecto asimétrico provocado por una progresión de rectángulos de diferentes anchos con los cuales Xenakis buscaba la abstracción a partir de la línea recta y la repetición. Para ello, recurrió al concepto de Modulor, que Le Corbusier había desarrollado a través de dos obras publicadas en 1948 y 1953 respectivamente, en las que continuaba la búsqueda de una relación matemática entre las medidas del hombre y de la naturaleza en la dirección abierta por los grandes arquitectos clásicos como Vitruvio, Da Vinci y Alberti.

El Modulor es un sistema modular antropométrico y, por tanto, un instrumento que permite encontrar la medida adecuada de las cosas que rodean al hombre de acuerdo con su estructura física. No en vano, su mismo nombre inevitablemente trae ecos del segundo componente musical identificado por Schelling: la modulación, porque, igual que ella, esta herramienta pone en juego distintos elementos que se relacionan con otro (el hombre), que permanece siendo el mismo aunque en movimiento, como si de esta unidad viva surgiera lo plural y se acomodara a ella.

El Modulor da pautas para efectuar la síntesis de unidad y pluralidad atendiendo a la modulación, de modo que busca lo que Schelling denominó "armonía", o -según Le Corbusier- facilita la ejecución de esos principios armónicos que la arquitectura comparte con la música. En consecuencia, no llama la atención que Le Corbusier iniciara su ensayo escribiendo sobre la modulación en la música y no, en la arquitectura:

El sonido es un suceso continuo que va, sin ruptura, desde lo grave a lo agudo. La voz puede emitirlo y modularlo, lo mismo que algunos instrumentos como, por ejemplo, el violín y también la trompeta (ambos instrumentos son considerados por la mayoría de los estudiosos como "celestiales", pues, son muy numerosas las representaciones pictóricas del barroco en las que aparecen asociados a las potestades angélicas); pero otros [instrumentos] son incapaces de ello, porque pertenecen a un orden humanamente organizado sobre intervalos artificiales: el piano, la flauta, etcétera. ${ }^{56}$

Por lo mismo, tampoco es digno de asombro que, llegados al capítulo 3, que se ocupa de las matemáticas, aclarase: “[...] la arquitectura se juzga con los ojos que ven, con la cabeza que gira, con las piernas que andan y con los oídos que oyen. La arquitectura, por consiguiente, no es un fenómeno sincrónico

\footnotetext{
${ }^{56}$ Le Corbusier, "Preámbulo", en El Modulor. Barcelona, Poseidón, 1976, cap. 1.
} 
sino sucesivo, hecho de espectáculos que se suman unos a otros y se suceden en el tiempo y en el espacio, como la música". ${ }^{77}$

Precisamente por eso, el sistema del Modulor se funda en la matemática. Se basa en el cuadrado, el doble cuadrado (que para Le Corbusier es una representación geométrica de la octava musical), la sección áurea, la serie de Fibonacci y el ángulo recto. Pero, además, contiene un factor estético decisivo que vincula el arte con la naturaleza, puesto que el número de oro define la proporción de las partes de la figura humana en la escultura griega y la serie numérica de Fibonacci crea elipses que, por ejemplo, rigen la implantación de pétalos y sépalos en las flores, así como el diseño de las volutas en las caracolas.

En la parte inferior de la fachada, el ritmo se plasma en los ventanales, en un sistema de paneles de vidrio asimétricos, separados por maineles de hormigón irregularmente distribuidos, el famoso "ondulatoire", ${ }^{58}$ que Le Corbusier repitió varias veces más, por ejemplo, en el edificio del Secretariado de Chandigarh (India) o en el Centro Carpenter del campus de la Universidad de Harvard (Estados Unidos). Entre algunos de los travesaños se insertan hojas pivotantes de aluminio que se asemejan a los alerones de los aviones y se encuentran situadas en posición vertical para favorecer la ventilación.

Los paneles muestran un proceso de composición serial basado otra vez en el Modulor, es decir, que son dinámicos y, por tanto, están relacionados con las proporciones del organismo humano y con la música, en cuanto arte del tiempo. Como otros elementos arquitectónicos, tienen una función: de iluminación y acondicionamiento climático, pero también un fin expresivo que remite a lo espiritual, a la integración con el cosmos, ya que dejan contemplar la evolución de la luz durante las distintas horas del día, constituyendo en sí mismos un fenómeno plástico de percepción sinestésica.

Curiosamente, cuando a Le Corbusier se le propuso el diseño del monasterio afirmó que su objetivo sería el de "alojar a un centenar de monjes y procurarles el silencio"; ${ }^{59}$ pero, al colaborar con Xenakis, no sólo construyó un edificio que rezumaba la abstracción de la meditación en conjunción con el poder creador de la naturaleza, haciendo emerger desde el paisaje las formas arquitectónicas puras, construyendo una poética de la luz y convirtiendo la techumbre en un campo de hierba. Gracias a Xenakis, esos brutales volúmenes de hormigón que dieron nombre a una de sus etapas creativas, terminaron configurando el espacio musicalmente, como un universo pitagórico, porque el "ondulatoire" casi se podría ejecutar, ya que es algo así como un pentagrama

${ }^{57}$ Ibid., cap. 3, p. 70.

${ }^{58}$ Llamado así debido a la ondulación que se percibe a causa de la densidad de los marcos

${ }^{59}$ Apud J. Petit, Un couvent de Le Corbusier. París, Éditions Minuit, 1961, pp. 17 y ss. 
rítmico para un inmenso xilófono donde los paneles representan el silencio y los parantes el sonido.

Por último, en su afán de mostrar el carácter especular que la arquitectura presenta ante la música, Schelling interpreta los distintos órdenes de columnas griegas bajo el prisma de la triple distinción de ritmo, armonía y melodía:

El orden dórico, por ser el más antiguo, es también el más sencillo. Mantiene sólo lo esencial, lo estrictamente necesario y esquemático, por eso, se asimila al ritmo, siendo "el más severo, realista y varonil de los tres sin desarrollo a lo ancho". ${ }^{60}$ Como Schelling intenta probar que el origen de la arquitectura se encuentra en la música, sostiene que los triglifos tienen la forma de una lira y que su número alude al sistema tonal griego más antiguo, una comparación que, a partir de entonces, se volvió prácticamente un lugar común en la historia de la arquitectura y que terminó por relacionar el primer orden con el mito de la lira de Anfión, cuyo sonido movió las piedras hasta unirlas formando los muros de la ciudad de Tebas. El recurso a Vitruvio le sirve para confirmar la perfecta concordancia de las proporciones de esta columna con las relaciones musicales, por ejemplo, entre el ancho y la altura de los triglifos.

Frente al anterior, el orden jónico resulta ideal, alegórico y, en cierto sentido, se acerca a la pintura por la utilización de la línea curva, por eso, representa la armonía. Según refiere Vitruvio, las proporciones de la columna (ocho veces más alta que el ancho del tronco) coinciden con las de una mujer, las volutas aluden al peinado femenino y las estrías recuerdan los pliegues de los vestidos. A Schelling esto le parece una simple suposición, aunque en el fondo le viene muy bien, ya que coincide con su atribución del segundo elemento de la tríada a lo femenino, como puede verse en otras partes de la Filosofía del arte. ${ }^{61}$ Lo que más le interesa sobre el tema de las proporciones es que expresan la armonía musical más perfecta: el triple acorde armónico. En cuanto al remate de la columna jónica, considera que las ondulaciones preludian lo orgánico en lo inorgánico y constituyen presagios de formas animales, es decir, de formas superiores a las vegetales (que son las que debería reflejar la arquitectura), de esas formas orgánicas que serán todo el centro de atención en el bajorrelieve, que es la siguiente de las artes plásticas en la clasificación . ${ }^{62}$

El último de los órdenes, el corintio, es melódico y surge de la síntesis del ritmo y la armonía, ${ }^{63}$ por eso, responde a las proporciones en el tránsito de la

${ }^{60}$ F. W. J. Schelling, Filosofía del arte, p. 309.

${ }^{61}$ Ibid., pp. 99-101 y 103 y ss.

${ }^{62}$ Ibid., pp. 312-313.

${ }^{63}$ Obsérvese que en este punto Schelling maneja una definición distinta de melodía. Antes había considerado que era la síntesis del ritmo y la modulación subordinada a la primera unidad. Ahora incluye en la síntesis a la armonía, que ya introdujo para caracterizar el orden jónico. 
figura masculina a la femenina, o sea, en el cuerpo de una doncella. Nuevamente, Vitruvio es el referente para explicar el mito asociado al nacimiento de este estilo: tras la muerte de una joven a punto de casarse, su ama puso sobre el túmulo una canasta con vasijas queridas por la difunta que, sin querer, colocó sobre una planta de acanto que creció en primavera. La imagen sirvió de inspiración para la construcción del capitel corintio al arquitecto Calímaco, quien vio la canasta revestida de hojas de acanto al pasar por allí. Como ocurre en la música melódica, se trata de un estilo que reúne la variedad con un cierto amaneramiento y donde aparecen también más contrastes que en los órdenes anteriores, entre lo recto y lo redondo, lo liso y lo sinuoso, lo ingenuo y lo artificial.

De este modo, limitándose a buscar sus ejemplos en la arquitectura clásica, Schelling desarrolla la idea de que ella es música congelada. Sin embargo, sus explicaciones no son circunstanciales ni valen sólo para los modelos que presenta.

Se basan en lo esencial, en aquello que internamente conecta a cada obra y estilo artístico con el conjunto de la realidad, implicándolos dentro de un sistema dinámico de referencias cruzadas en el que cada una de las artes refleja a las demás mientras todas ellas espejan la naturaleza, que, a su vez, es reflejo del mundo de las ideas y del absoluto contraído en ellas. Todo está en todo, porque el universo es una grandiosa teofanía y, por eso, al crear, el artista hace un servicio divino. Lo interesante del caso es que muchas de sus ideas las hemos vuelto a encontrar en los padres de la arquitectura moderna, en el contexto de una práctica artística que, en principio, desde un punto de vista externo, formal, poco tiene que ver con la época elegida como modélica por el filósofo. Con seguridad, ni Le Corbusier ni Xenakis habían leído la estética de Schelling, pero ambos estaban familiarizados con las dos artes relacionadas y sus respectivas estructuras. De hecho, tanto la madre como el hermano de Le Corbusier eran músicos y el propio Xenakis era compositor. Además, los dos conocían bien los desarrollos de la arquitectura griega y sus relaciones matemáticas (especialmente Xenakis, por su nacionalidad y profesión), de modo que sentían esa admiración por lo clásico compartida por Schelling. Sin embargo, no deja de ser asombroso que el tratamiento que el filósofo hace de las artes particulares y su interrelación sea el resultado de una construcción sistemática totalmente $a$ priori, que no recurre a la experiencia para justificarse sino sólo para confirmar lo que ha establecido de antemano, porque esto convierte la práctica de Le Corbusier y de Xenakis, sus obras y sus ideas, en prueba y testimonio de la concepción de aquél sobre el arte y el universo. Como afirma Schelling en el Sistema del idealismo trascendental, el artista y el filósofo tienen algo en común que los une secretamente y les otorga una visión muy parecida de las cosas, porque la intuición estética es sólo la intuición intelectual objetivada. Y si esto es así, 
[...] es evidente que el arte es el único órgano verdadero y eterno, y a la vez, el documento de la filosofía que atestigua siempre y continuamente lo que la filosofía no puede presentar exteriormente, a saber, lo no consciente en el actuar y en el producir y su originaria identidad con lo consciente. Por eso mismo, el arte es lo supremo para el filósofo, porque $[. .$.$] le abre el santuario donde arde en una única llama, en eterna$ y originaria unión, lo que está separado en la naturaleza y la historia y que ha de escaparse eternamente en la vida y en el actuar así como en el pensar. La visión que el filósofo se hace artificialmente de la naturaleza es para el arte la originaria y natural. Lo que llamamos naturaleza es un poema cifrado en maravillosos caracteres ocultos. Pero si se pudiera desvelar el enigma, reconoceríamos la odisea del espíritu que, burlado prodigiosamente, huye de sí mismo mientras se busca, pues mediante el mundo sensible, $[\ldots]$ como a través de una niebla sutil, el sentido ve el país de la fantasía al que aspiramos. ${ }^{64}$

${ }^{64} \mathrm{~F}$. W. J. Schelling, Sistema del idealismo trascendental, en Sämmtliche Werke, t. III, pp. 627 y ss. 